\title{
STUDIES OF THE EFFECT OF DIETARY PROTEIN AND CALORIC LEVELS ON THE KINETICS OF NITROGEN METABOLISM USING $\mathrm{N}^{15}$ L-ASPARTIC ACID
}

\author{
By DONALD P. TSCHUDY, HABEEB BACCHUS, SHERMAN WEISSMAN, \\ DONALD M. WATKIN, MARJORIA EUBANKS \\ AND JULIUS WHITE
}

(From the Metabolism Service, General Medicine Branch, and the Laboratory of Physiology, National Cancer Institute, National Institutes of Health, Bethesda, Md.)

(Submitted for publication October 17, 1958; accepted February 5, 1959)

There have been relatively few attempts to study the dynamic aspects of nitrogen metabolism from the standpoint of the intact overall organism. The complexity of the problem precludes an exact mathematical description at present, but models which purport to enable one to compute values for nitrogeneous metabolic pool size and rate of incorporation of nitrogen into the human have been devised by San Pietro and Rittenberg (1) and Olesen, Heilskov and Schoenheyder (2). The approach of San Pietro and Rittenberg was to devise a model on biologic grounds and describe the model by equations, whereas that of Olesen and co-workers was to derive a model from experimental data which could be described by certain equations. The latter, by extending the length of time of the experiment, changed the nature of some of the necessary assumptions of the San Pietro-Rittenberg type model. While there are certain advantages and disadvantages inherent in both types of approach, it would appear that the San Pietro-Rittenberg approach is as satisfactory as any yet available.

The purpose of this study of the San PietroRittenberg model was to determine: 1 ) the reproducibility of calculated values for nitrogenous metabolic pool size $(\mathrm{P})$, rate of nitrogen incorporation into the protein of the organism (S), and rate constant for metabolic pool turnover (B) in one individual under the same experimental conditions, and 2) the effects of variation of caloric and protein content of the diet on the calculated values. Further mathematical manipulations of the original equations have led to an expression which allows the computation of $\mathrm{B}$ at any time, thus providing further insight into the model.

\section{METHODS AND MATERIALS}

The patient was a 53 year old white female with histologically proven lymphosarcoma of three and one-half years duration. She had been treated with radiotherapy on a number of occasions, the last course of treatment having been completed six weeks before admission. At the time of admission her spleen was palpable one finger-breadth below the costal margin, but there was no significant adenopathy or other evidence of lymphosarcoma. During the 84 days of the study there was no evidence of tumor growth and only a slight weight change. She was afebrile during all eight studies. Radioactive iodine uptake and protein bound iodine determinations were in the lower range of normal.

Metabolic balance studies were performed during her entire hospitalization (see Figure 1) by methods previously described (3). Caloric expenditure determinations were performed by the technique of Johnson and Newburgh (4). Four pairs of duplicate studies of the model were performed on four different diets. Diet I consisted of 1,800 calories with $40 \mathrm{Gm}$. of protein; Diet II contained 1,200 calories and $40 \mathrm{Gm}$. of protein; Diet III contained 1,200 calories and $80 \mathrm{Gm}$. of protein; and Diet IV, 1,800 calories and 80 $\mathrm{Gm}$. of protein. Two studies were performed on each diet, the first after eight days of equilibration with the diet and the repeat study eight days later. The first study on Diet I was performed after 12 days of equilibration. Each study was performed after the oral administration with breakfast of $100 \mathrm{mg}$. of excess $\mathrm{N}^{15}$ as L-aspartic acid (1.508 $\mathrm{Gm}$. of 63.0 atom per cent excess $\mathrm{N}^{15} \mathrm{~L}$-aspartic acid for Studies 1 through 6, and $0.995 \mathrm{Gm}$. 95.5 atom per cent excess $\mathrm{N}^{15} \mathrm{~L}$-aspartic acid for Studies 7 and 8). L-Aspartic acid was prepared by the method of $\mathrm{Wu}$ and Rittenberg (5). Urine was collected at 20 minute intervals for the first four hours, at $\mathbf{3 0}$ minute intervals for about the next three hours, and at wider intervals thereafter (Table II). The specific activity curve of urinary urea was determined on urea isolated by xanthydrol precipitation (6). Urea excretion was determined by the urease method followed by Nesslerization (7). The "urea pool" was measured on two occasions (Studies 1 and 4) by body water determination using tritium oxide ${ }^{1}(8)$. Total nitrogen excretion was determined by the Kjeldahl method (9).

\footnotetext{
${ }^{1}$ The authors wish to thank Drs. N. Berlin and D. Nathan for the body water determinations, and Mr. A. McNish for mass spectrometer determinations.
} 


\section{RESULTS AND DISCUSSION}

The problem of understanding the model and its limitations is that of relating the mathematics to biological meaning. Because of the limitations inherent in the assumptions on which the mathematics is based, the values of B (rate constant for metabolic pool turnover), $\mathrm{P}$ (metabolic pool size as grams of $\mathrm{N}$ ), and $\mathrm{S}$ (the grams of $\mathrm{N}$ incorporated into the protein of the organism per day) undoubtedly do not represent the true values of these parameters of nitrogen metabolism as originally defined. The exact meaning of the computed values cannot be defined, but it seems probable that the values for $\mathrm{P}$ and $\mathrm{S}$ do not represent the entire body, but only a portion, i.e., its more dynamically active constituents. Information pertaining to these constituents, however, may be of equal or perhaps greater importance than that pertaining to the entire body. While the calculated value for $\mathrm{P}$ is quite similar to the product of extracellular free amino acid nitrogen and body water, a more correct value of $\mathrm{P}$ is probably greater than this because of the significantly higher intracellular concentration of amino acids.

Stated in biological terms, there are six major assumptions upon which the equations of the San Pietro-Rittenberg model are based. The assumptions inherent in the model are:

1) There is one nitrogenous metabolic $(P)$ and one urea $(U)$ pool in the body, or there are $\mathrm{X}$ pools in sufficiently rapid equilibrium to be considered as single pools.

2) The size of the nitrogenous metabolic pool $(\mathrm{P})$ and the urea pool (U) are constant during the course of the experiment and urea and total nitrogen are excreted at a uniform rate during the day. It is important to realize that the assumption of $\mathrm{P}$ and $\mathrm{U}$ being constant is only necessary "during the course of the experiment." The measurements involving isotopes which are used for the solution of Equation 16 (1) for B and then the solutions of $\mathrm{P}$ and $\mathrm{S}$ are completed in about five to six hours, although the nonisotopic measurements $\left(E_{u} \text { and } E_{t}\right)^{2}$ are over a 24 hour period. It is probably safe to assume $\mathrm{U}$ to be a constant. Whether there is significant

\footnotetext{
${ }^{2} E_{u}$ is the number of grams of urea nitrogen excreted per day; $E_{t}$ is the number of grams of total nitrogen excreted per day.
}

variation in $\mathrm{P}$ during the experiment is unknown, but it seems likely that there is some temporary increase in $\mathrm{P}$ following the ingestion of a meal. In previous studies (1) the dose of nitrogen given as isotopic amino acid was significant relative to the computed size of the metabolic pool, whereas in the present studies it varied between 4.0 and 9.7 per cent of the computed size of the metabolic pool. The question arises as to whether nitrogen equilibrium is necessary for the model to be valid. It should be noted that $\mathrm{D}$ (grams of dietary nitrogen per day) appears nowhere in the equations used to calculate $\mathrm{B}, \mathrm{P}$ and $\mathrm{S}$. If the basic assumption is made that $\mathrm{P}$ is a constant during the course of the experiment, then the model would theoretically be valid for positive and negative nitrogen balance for the following reasons: Stating that $\mathrm{P}$ is a constant is equivalent to stating that $\mathrm{D}+\mathrm{R}=\mathrm{S}+\mathrm{E}_{\mathrm{t}}{ }^{3}$ The assumption of $\mathrm{P}$ being a constant eliminates any use of the diet as an individual variable, since it is only important for $\mathrm{D}+\mathrm{R}=\mathrm{S}+\mathrm{E}_{t}$, which in turn must be constant during the experiment. The case of nitrogen equilibrium is merely where $\mathrm{D}=\mathrm{E}_{\mathrm{t}}$ and $\mathrm{S}=\mathrm{R}$. In positive nitrogen balance $D>E_{t}$ and $S>R$, but if $P$ is constant, then $\mathrm{D}+\mathrm{R}$ still $=\mathrm{S}+\mathrm{E}_{\mathrm{t}}$. $\mathrm{F}^{4}$ would presumably be increasing by a value of $D-E_{t}$ or $\mathrm{S}-\mathrm{R}$. If one assumes that $\mathrm{P}$ is only constant during nitrogen equilibrium, then the model is theoretically valid only for nitrogen equilibrium. The patient reported in the present study was very close to nitrogen equilibrium in the last four studies (within $0.25 \mathrm{Gm}$. N per day on Studies 5,6 and 7, and $0.5 \mathrm{Gm}$. N per day on Study 8) (Figure 1) and in slightly negative nitrogen balance in the first four (1 Gm. $\mathrm{N}$ per day).

3) $\mathrm{N}^{15}$ after administration is instantaneously distributed throughout the metabolic pool in the same distribution pattern as unlabeled nitrogen. This is intimately related to Assumption 1. When a single labeled amino acid is used (as was done here), this distribution of isotope throughout the metabolic pool involves three separate processes: a) the distribution of $\mathrm{N}^{15}$ among the other amino acids of the metabolic pool by trans-

\footnotetext{
${ }^{3} \mathrm{D}$ is defined as the grams of dietary nitrogen per day; $R$ is the number of grams of nitrogen returned to the metabolic pool per day through breakdown of protein.

${ }^{4} \mathrm{~F}$ is the number of grams of protein nitrogen in the body.
} 
4 DAY PERIOD

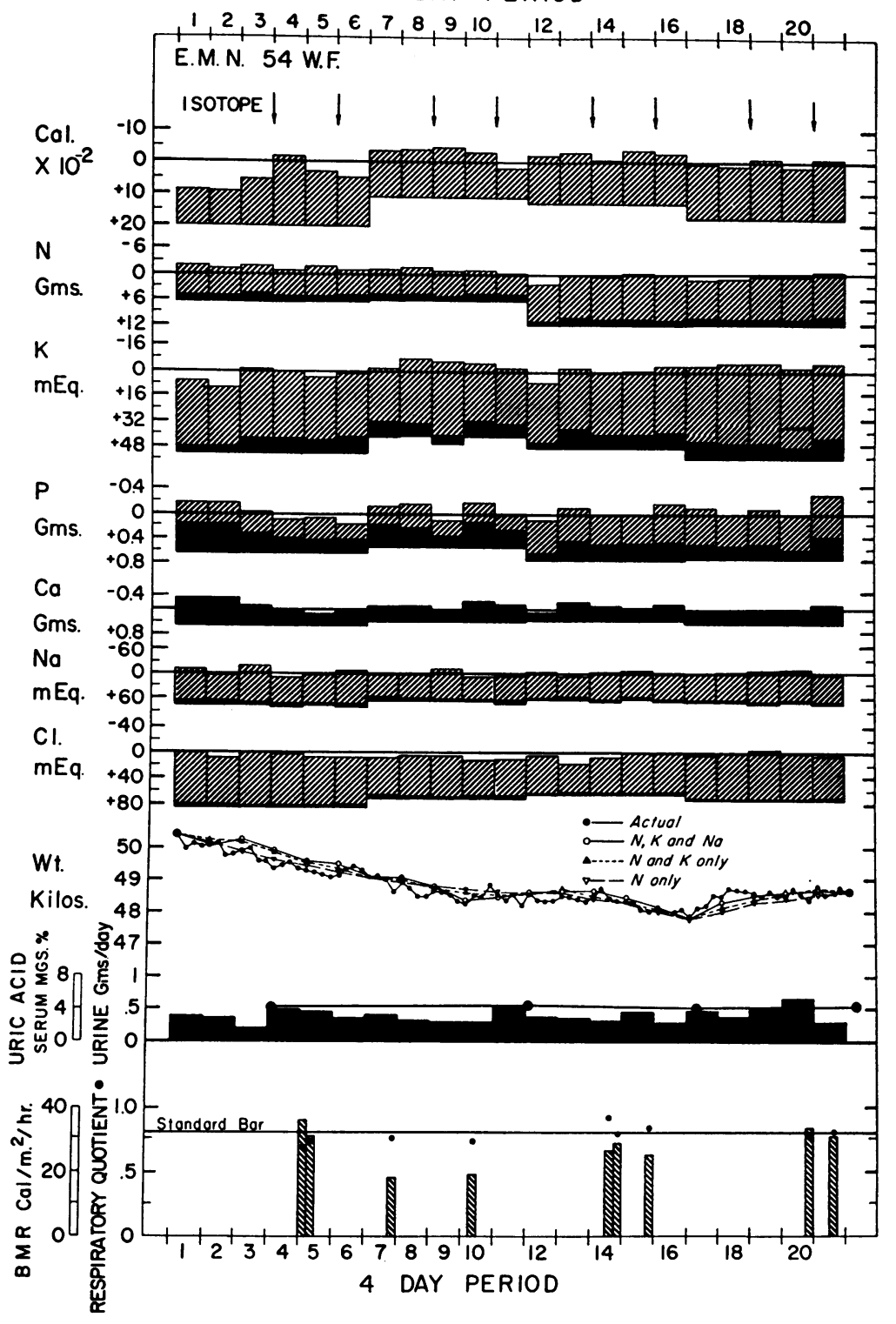

Fig. 1. Metabolic Balances in a 54 Year Old Woman with Clinically Inactive Lymphosarcoma ON VARIOUS DiETS

The first seven bar graphs in the chart present balance data according to the general scheme proposed by Reifenstein, Albright and Wells (14). Intake is plotted downward from the zero line; output in terms of feces and urine is then plotted upward from the point representing intake. When total output touches the zero line, equilibrium or balance is represented; when output fails to reach the zero line, positive imbalance is represented; and when output extends beyond the zero line, negative imbalance is represented. The ordinates of the nitrogen, potassium, phosphorus and calcium graphs are so selected that equal heights represent the approximate ratios at which these elements exist in normal protoplasm and bone, i.e., $3 \mathrm{Gm}$. of nitrogen to $8 \mathrm{mEq}$. of potassium to $200 \mathrm{mg}$. of phosphorus (protoplasm) and $400 \mathrm{mg}$. of calcium to $200 \mathrm{mg}$. of phosphorus (bone). The ordinates of the sodium and chloride graphs are so selected that equal heights represent the approximate ratios at which these elements exist in normal extracellular fluid, i.e., $150 \mathrm{mEq}$. of sodium to $100 \mathrm{mEq}$. chloride.

Below the bar graphs, line graphs record the patient's weight. The solid line connecting the closed circles records the actual weight measured daily. The solid line connecting the open circles depicts the theoretical weight based on considerations of the gain or loss of intracellular and extracellular fluid quantified by balances of nitrogen, potassium and sodium. The broken line joining the closed triangles depicts the theoretical weight based on considerations of gain 
amination, $b$ ) mechanical mixing of these labeled amino acids from one organ to another, and $c$ ) entrance into cells. This assumption of instantaneous distribution of $\mathrm{N}^{15}$ throughout the metabolic pool is incorrect because of these considerations. The first objection (the finite time involved in transamination) could be partially overcome by using a mixture of labeled amino acids such as that obtained from hydrolysate of labeled protein. Thus, transamination of the isotope would have occurred prior to its administration to the patient. Intravenous administration of the isotope would tend to decrease the error of mechanical mixing. Since the liver removes a large fraction of the administered dose of labeled amino acid, it is probable that the values computed from the model are to a large extent a reflection of liver activity.

4) Nonurea nitrogen which is excreted (denoted by $E_{\mathbf{x}}$ ) comes directly from the metabolic pool. This is true with several exceptions such as uric acid and creatinine, which are not really components of the metabolic pool as defined here. Examination of the equations reveals that the compartment of origin of $E_{\mathbf{x}}$ does not effect the equations or the computed values, except for the computation of $S$, where $E_{t}$ is subtracted from $B P$. The calculated value of $S$ is the total amount of nitrogen leaving the metabolic pool (BP), minus that excreted from the metabolic pool into the urine (assumed in the model to equal $E_{t}$, but actually somewhat less than $E_{t}$ because certain components of $E_{t}$ such as uric acid and so forth are not excreted from the metabolic pool as defined here). This error tends to decrease the value of $S$ somewhat below the true value. The above discussion pertains when $S$ is defined as the total amount of nitrogen incorporated into the organism per day. This would include nucleic acids and other nonprotein materials. If $S$ is defined as the grams of nitrogen incorporated into protein only, then this assumption introduces much less error, because the computed value of $S$ would not include these nonprotein materials. The subtraction of the nonmetabolic pool component of $E_{x}$ from $B P$ would decrease $S$ by a value equal to the nonprotein nitrogen incorporated in the steady state.

5) The amount of isotope returned to the metabolic pool from protein, which during the course of the experiment had incorporated $\mathrm{N}^{15}$, is negligible. This assumption corresponds to neglecting the term $Q \mathrm{dt}$ in Equation 1 (1). Since the crucial isotope measurements are made in about six hours, it is not difficult to accept this assumption on the basis of present day knowledge. From the data of San Pietro and Rittenberg (1) in Experiment DR-1, the value of the integral of $Q \mathrm{dt}$ over a six hour period is roughly estimated as about 5 per cent of the administered dose of isotope $\left(\frac{S+E_{u}}{E_{u}} \times \frac{3.7}{4}\right)$. This is based on the assumption that the integral of $Q \mathrm{dt}$ is a linear function of time, which is

or loss of intracellular fluid quantified by balances of nitrogen and potassium. The broken line joining the open triangles depicts the theoretical weight based on considerations of gain or loss of intracellular fluid based on nitrogen balance alone.

The line graph below the weight curves represents the serum uric acid level and the bar graph, the daily excretion of uric acid.

The bar graphs at the bottom of the chart represent the patient's basal metabolic rate and the closed circles the respiratory quotient on selected days during the study (15). The line labeled "standard bar" represents the AubDubois standard basal metabolic rate for a woman of the age and with the surface area of this patient and also the respiratory quotient of a patient consuming an average mixed diet.

The Arabic numerals along the top and bottom of the chart refer to the four day metabolic balance periods of the study and may be identified with the isotope studies and diets by reference to the arrows at the top of the chart and to Tables I through V.

Note that low protein intake at both calorie levels was associated with weight loss and negative nitrogen imbalance. High protein intake was associated with nitrogen equilibrium at both levels of caloric intake, but was accompanied by caloric equilibrium and weight gain only when the caloric intake was high. The calcium balances suggest more retention of calcium on the high calorie, high protein, than on other regimens.

The actual and theoretical weight curves are practicably superimposable on one another. Uric acid excretion rose when calorie intake was increased while the patient ingested a high protein intake.

The basal metabolic rate declined dramatically on the low calorie, low protein regimen, rose on the high calorie, low protein, and returned to standard when the calorie and protein intake were both high. The respiratory quotient was lower on low than on high protein regimens. 


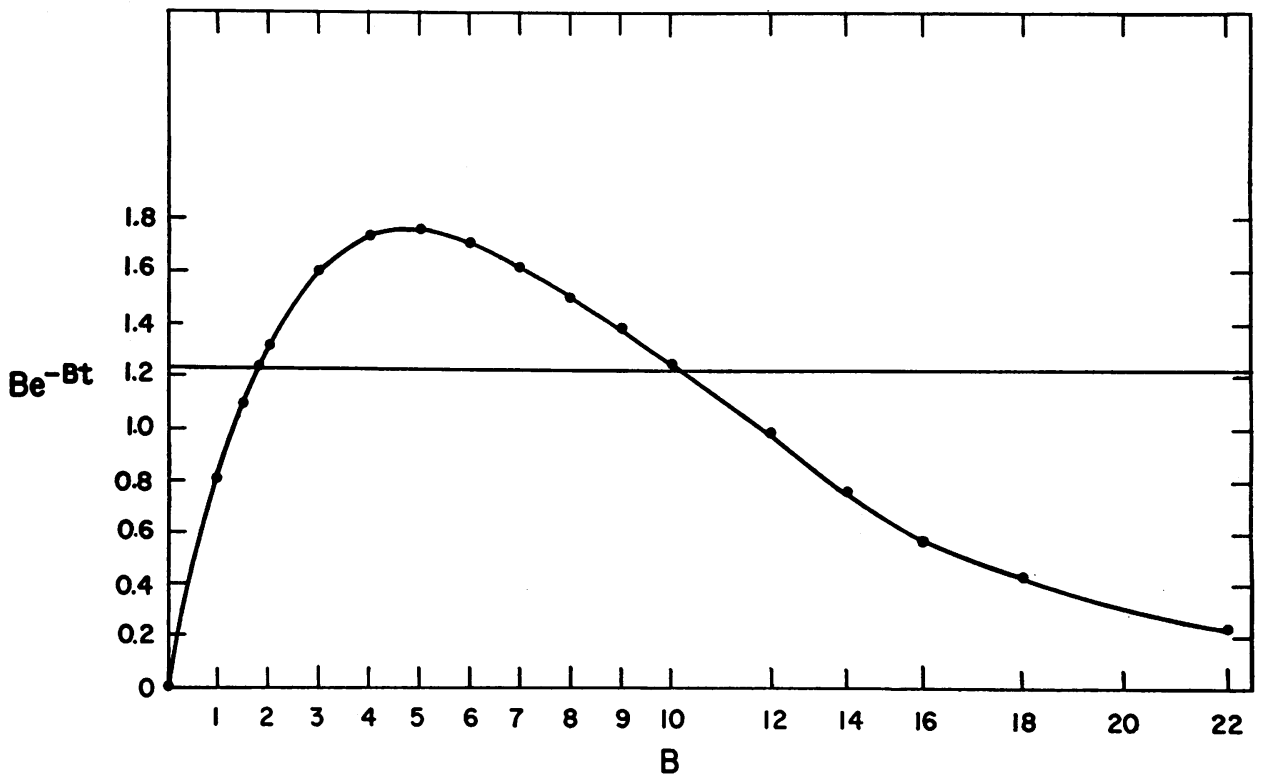

Fig. 2. The Curve of the Expression $B^{-B t}$ as a Function of B where t Equals 0.208

only an approximation. While this is not completely negligible, it introduces no great error over this period of time.

6) The overall processes involved in the model can be described by first order kinetics. This problem has been discussed by Reiner $(10,11)$.

The rate constant for metabolic pool turnover (B) can be computed in several ways. Before discussing these methods it should be pointed out that the model assumes $B$ to be a constant since $B=\frac{E_{t}+S}{P}$ where $E_{t}, S$ and $P$ are assumed to be constants. San Pietro and Rittenberg solve for $B$ by equating the derivative of the expression for isotope concentration in the urea pool to zero at the time of maximum isotope concentration. This leads to the expression $\frac{E_{u}}{U} e^{-\left(E_{u} t \max / U\right)}=B e^{-B t \max }$. Casual examination would suggest that this is an identity in which $B=\frac{E_{u}}{U}$, which would appear to be a contradiction of the original definition of $B$. It is readily seen however, as shown in Figure 2, that for a given value of $t \max (0.208$ was used), when $\frac{E_{u}}{U} e^{-\left(E_{u} t \max / U\right)}$ is plotted as a function of $B$, there are two values of $B$ which satisfy a given value (1.23 for Study 2) of $\frac{E_{u}}{U} e^{-\left(E_{u} t \max / U\right)}$ below the maximum point of the curve. One of these is $\frac{E_{u}}{U}$, the other being the value sought here.

Figure 2 demonstrates the values of $B$ which satisfy the conditions in Study 2 where $t$ max $=$ 0.208 days and $\frac{E_{u}}{U}=1.805$.

Thus, the San Pietro-Rittenberg method allows the computation of $\mathrm{B}$ at only one time point during the experiment since the equation used for this computation is true only at the time of maximum specific activity of urea. An equation which enables one to compute $B$ at any time (provided data for twice that length of time are available) can be derived from the equation for the concentration of isotope in the urea pool as follows:

$$
\begin{gathered}
\mathrm{C}_{\mathrm{u}} \text { (as atom per cent excess, where } \lambda o=\text { grams } \\
\text { of } \left.\mathrm{N}^{15} \text { excess given at } \mathrm{t}=0\right)= \\
\frac{100 \lambda_{o} E_{u}}{\mathrm{P}\left(\mathrm{E}_{\mathrm{u}}-\mathrm{BU}\right)}\left(\mathrm{e}^{-\mathrm{Bt}}-\mathrm{e}^{-\left(\mathrm{E}_{\mathrm{u}} \mathrm{t} / \mathrm{U}\right)}\right)
\end{gathered}
$$

Let

$\frac{100 \lambda_{o} E_{u}}{P\left(E_{u}-B U\right)}=x, \quad e^{-B}=y \quad$ and $e^{-E_{u} / U}=D$.

Also let

$$
t_{2}=2 t_{1} \text { and } \begin{aligned}
& C_{u}\left(t_{1}\right)=C_{u 1} \\
& \\
& C_{u}\left(t_{2}\right)=C_{u 2} .
\end{aligned}
$$


Then

$$
\begin{aligned}
& \mathrm{C}_{\mathrm{u} 1}=\mathrm{x}\left(\mathrm{y}^{\mathrm{t}_{1}}-\mathrm{D}^{\mathrm{t}_{1}}\right) \\
& \mathrm{C}_{\mathrm{u} 2}=\mathrm{x}\left(\mathrm{y}^{\mathrm{t}_{2}}-\mathrm{D}^{\mathrm{t}_{2}}\right)=\mathrm{x}\left(\mathrm{y}^{2 \mathrm{t}_{1}}-\mathrm{D}^{2 \mathrm{t}_{1}}\right) \\
& \frac{\mathrm{C}_{\mathrm{u} 2}+\mathrm{x} \mathrm{D}^{2 \mathrm{t}_{1}}}{\left(\mathrm{C}_{\mathrm{u} 1}+\mathrm{xD}^{\mathrm{t}_{1}}\right)^{2}}=\frac{\mathrm{x} \mathrm{y}^{2 \mathrm{t}_{1}}}{\mathrm{x}^{2} \mathrm{y}^{2 \mathrm{t}_{1}}}=\frac{1}{\mathrm{x}} \\
& \mathrm{C}_{\mathrm{u} 2} \mathrm{x}+\mathrm{x}^{2} \mathrm{D}^{2 \mathrm{t}_{1}}=\mathrm{C}_{\mathrm{u} 1}{ }^{2}+2 \mathrm{x} \mathrm{D}^{\mathrm{t}_{1}} \mathrm{C}_{\mathrm{u} 1}+\mathrm{x}^{2} \mathrm{D}^{2 \mathrm{t}_{1}} \\
& x=\frac{C_{u 1}{ }^{2}}{C_{u 2}-2 C_{u 1} D^{t_{1}}} \text {. } \\
& \mathrm{y}^{\mathrm{t}}=\frac{\mathrm{C}_{\mathrm{u}}}{\mathrm{x}}+\mathrm{D}^{\mathrm{t}} \\
& \mathrm{y}^{\mathrm{t}_{1}}=\frac{\mathrm{C}_{\mathrm{u} 1}}{\mathrm{x}}+\mathrm{D}^{\mathrm{t}_{1}}+\frac{\mathrm{C}_{\mathrm{u} 2}}{\mathrm{C}_{\mathrm{u} 1}}-\mathrm{D}^{\mathrm{t}_{1}} . \\
& =\frac{-\ln \left(\frac{\mathrm{C}_{\mathrm{u} 2}}{\mathrm{C}_{\mathrm{u} 1}}-\mathrm{e}^{\left(-\mathrm{E}_{\mathrm{u}} \mathrm{t}_{1} / \mathrm{U}\right)}\right)}{\mathrm{t}_{1}}
\end{aligned}
$$

where $\frac{\mathrm{C}_{\mathrm{u} 2}}{\mathrm{C}_{\mathrm{u} 1}}$ represents the ratio of isotope concentrations in the urea pool at any two times which are in a ratio of 2 to 1 . All the assumptions of the model (that $\mathrm{B}$ is a constant and so on) are inherent in the above equation for $\mathrm{B}$ at any time $t_{1}$, since this equation is derived entirely from the equation for $C_{u}$ from the model. If the assumptions on which the model is based were absolutely correct, the computed values of $\mathrm{B}$ plotted at different times would produce a straight line of zero slope, i.e., a constant. B was com-

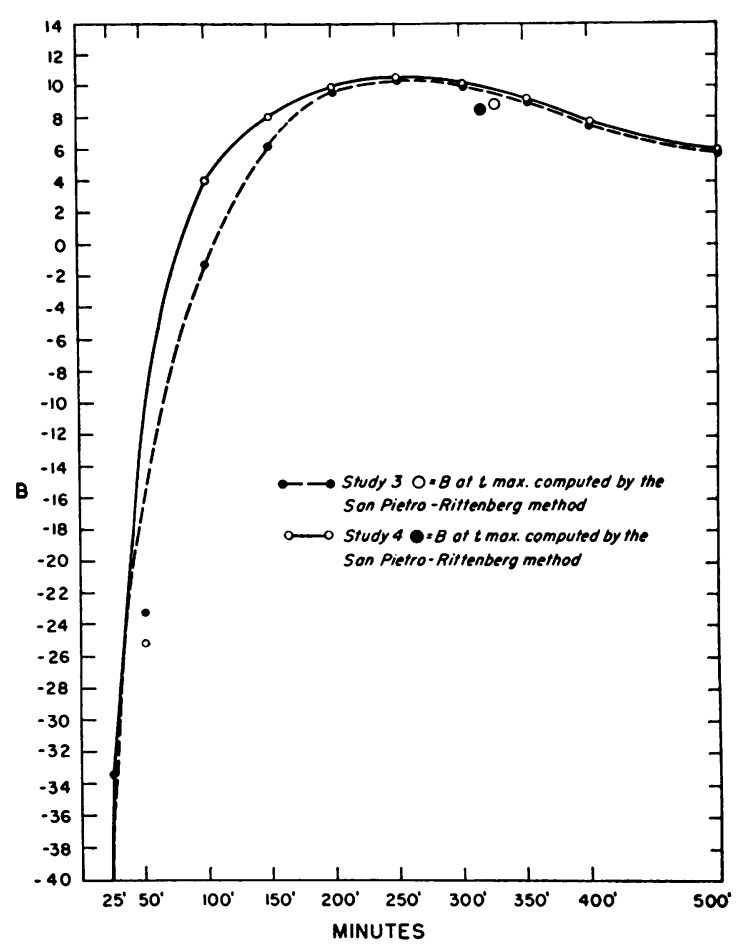

Fig. 3. Computed Values of B at Various Times DURING STUdies 3 aNd 4

puted at various time intervals in all eight studies.

The general shape of the curve from the dupli-

\begin{tabular}{|c|c|c|c|c|c|c|c|c|c|}
\hline \multicolumn{3}{|c|}{ Study $\ldots \ldots \ldots \ldots \ldots \ldots \ldots$} & 2 & 3 & 4 & 5 & 6 & 7 & 8 \\
\hline \multicolumn{10}{|c|}{$\begin{array}{l}\text { Time after adminis- } \\
\text { tration of isotope }\end{array}$} \\
\hline $\min$. & days & & & & & & & & \\
\hline 25 & 0.0174 & -80.2 & -96.2 & -33.3 & -61.1 & -24.72 & -26.73 & -18.6 & -30.53 \\
\hline 50 & 0.0348 & -18.6 & -31.7 & -23.3 & -25.1 & -35.2 & -19.74 & -3.83 & -32.7 \\
\hline 100 & 0.0696 & -1.42 & -25.9 & -1.19 & 4.11 & 0.273 & 1.98 & -2.57 & -0.14 \\
\hline 150 & 0.1041 & 6.03 & 6.32 & 6.17 & 8.05 & 5.41 & 7.53 & 9.58 & 15.33 \\
\hline 200 & 0.1394 & 10.86 & 8.54 & 9.58 & 9.88 & 8.96 & 11.16 & 13.27 & 17.26 \\
\hline 250 & 0.1736 & 11.76 & 9.54 & 10.31 & 10.47 & 13.1 & 12.16 & 13.34 & 21.03 \\
\hline 300 & 0.2082 & 9.92 & 9.78 & 10.00 & 10.18 & 13.6 & 9.93 & 10.02 & 22.64 \\
\hline 350 & 0.2431 & 8.0 & 9.04 & 9.04 & 9.12 & 10.18 & 7.78 & 7.75 & 16.53 \\
\hline 400 & 0.278 & 6.52 & 8.44 & 7.56 & 7.75 & 7.00 & 6.42 & 6.42 & 9.88 \\
\hline 500 & 0.347 & 5.18 & 7.39 & 5.99 & 5.90 & 4.08 & 5.04 & 4.69 & 5.18 \\
\hline
\end{tabular}
cate Studies 3 and 4 is demonstrated in Figure 3. The values for the other studies, where the agreement of duplicate curves was not quite so remarkable, is shown in Table I. The computed value of $B$ starts very early as a large negative value, increases rapidly to a positive value, reaches a maximum and gradually declines. Computation of $\mathrm{B}$ at various times from the

TABLE I

Computed values of $B$ at different times 


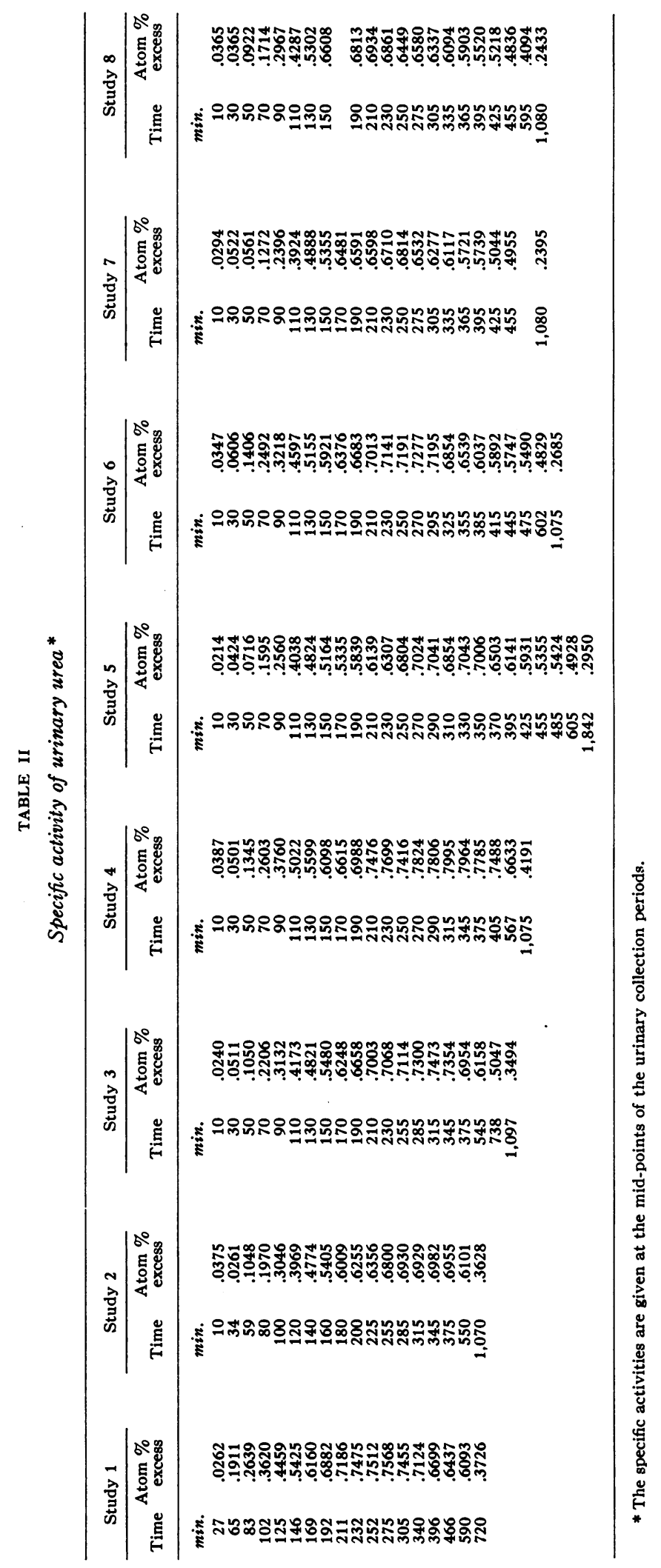


published data of San Pietro and Rittenberg (1) and Crispell (12) produces similar curves.

The fact that the computed values of B vary during the course of the experiment, as they do when the experimental data are used to compute $B$ at different times, means that the experimental data do not fit the equations of the model early in the experiment. This is a reflection of the fact that some of the assumptions on which the equations of the model are based are somewhat incorrect. The $t$ max (time of maximum urea specific activity) occurs at a time when there is not great deviation of $\mathbf{B}$ from linearity with zero slope, thus demonstrating that the use of $t \max$ for computation of B is justified.

The erroneous assumption which explains the early negative value of $B$ is that of instantaneous mixing of $\mathrm{N}^{16}$ throughout the metabolic pool. If this assumption were correct, $\lambda p$ would be expressed by a curve of the exponentially decreasing type with no ascending limb. The slope of this type of curve is negative throughout and equal to $-B \lambda$. $B$ for this type of assumed curve has a constant positive value. Experimentally, however, the curve of $\lambda p$ has an ascending limb and a descending limb, where the ascending limb corresponds to the period when isotope is entering $\mathrm{P}$ more rapidly than it is leaving. The slope prior to the maximum value of $\lambda p$ is positive and corresponds to the period when $B$ is negative which gives a positive value to the expression $-B \lambda p$. The time at which $B=0$ is the time of maximum value of $\lambda p$. Thereafter the positive value of $B$ corresponds to the negative slope of the curve of $\lambda \mathrm{p}$. The fact that $B$ decreases gradually after reaching a maximum value is a reflection of the fact that

TABLE III

Measurements used in computing $B, P$ and $S^{*}$

\begin{tabular}{lllll}
\hline \hline Study & Diet & E & $E_{\mathbf{u}}$ & U \\
\hline 1 & I & 5.16 & 6.32 & 2.46 \\
2 & I & 3.75 & 6.4 & 2.19 \\
3 & II & 4.85 & 5.17 & 2.46 \\
4 & II & 4.19 & 5.22 & 2.43 \\
5 & III & 7.66 & 8.98 & 3.51 \\
6 & III & 8.34 & 10.2 & 2.97 \\
7 & IV & 8.73 & 8.98 & 2.97 \\
8 & IV & 9.10 & 9.68 & 3.51 \\
\hline
\end{tabular}

* $E_{u}$ is the number of grams of urea nitrogen excreted per day; $E_{t}$ is the total grams of nitrogen excreted per day; and $U$ is the grams of urea nitrogen in the body.
TABLE IV

Values of $B, P$ and $S$ as computed from the time of maximum specific activity of urea *

\begin{tabular}{clcccc}
\hline \hline Study & Diet & B & P & S & BP \\
\hline 1 & I & 10.5 & 1.77 & 12.3 & 18.6 \\
2 & I & 10.36 & 1.65 & 10.7 & 17.1 \\
3 & II & 8.85 & 1.94 & 12.0 & 17.2 \\
4 & II & 8.95 & 1.63 & 9.40 & 14.6 \\
5 & III & 9.00 & 2.18 & 10.6 & 19.6 \\
6 & III & 9.05 & 2.52 & 12.6 & 22.8 \\
7 & IV & 10.00 & 2.60 & 17.0 & 26.0 \\
8 & IV & 14.24 & 1.80 & 15.9 & 25.6 \\
\hline
\end{tabular}

* $B$ is defined as the rate constant for metabolic pool turnover and is expressed in units of days ${ }^{-1} . P$ is the number of grams of nitrogen in the metabolic pool. $S$ is the number of grams of nitrogen incorporated into protein per day. BP is the turnover rate of the metabolic pool expressed as grams of nitrogen leaving the metabolic pool per day.

the specific activity curve of $\lambda p$ decreases less rapidly after $B$ max than the model would predict because of nonhomogeneity of the metabolic pool, in addition to the fact that isotope is entering the metabolic pool from various sources.

The specific activities of urinary urea for all eight studies are presented in Table II and the data on urea excretion, total nitrogen excretion and urea pool size are presented in Table III. The values for $\mathrm{B}, \mathrm{P}$ and $\mathrm{S}$ for all eight studies as computed by the San Pietro and Rittenberg method (1) are presented in Table IV. For Studies 1 through 6 , the reproducibility of the values of $B$ in duplicate studies is excellent. Reproducibility of $\mathrm{P}$ and $\mathrm{S}$ is generally within 20 per cent of the larger value. The accuracy of determination of the time of maximum isotope concentration in urea ( $t \max )$ is important, since the computed values of $\mathrm{B}$ and $\mathrm{P}$ are relatively sensitive to small changes in $t$ max as compared to $E_{u}$ and $U$. Thus, in Study 8, a decrease of 10 minutes in $t$ max (from 210 to 200 minutes) increases $B$ from 14.24 to 15.3 and decreases $P$ from 1.80 to 1.69 . In the present studies, the frequency of determinations of urea specific activity (every 20 minutes) enabled us to determine accurately the $t$ max.

It could be argued that since errors inherent in the assumptions tend to decrease the value of $B$, the most accurate value of $B$ is the maximum one. Using the maximum value of $B$ from the computed curve of $B$ as a function of time and the time corresponding to this value of $B$, the 
TABLE V

Values of $B, P$ and $S$ from the maximum value of $B$ as a function of time*

\begin{tabular}{llrccc}
\hline \hline Study & Diet & B & P & S & BP \\
\hline 1 & I & 11.8 & 1.64 & 13.0 & 19.3 \\
2 & I & 9.8 & 1.73 & 10.6 & 17.0 \\
3 & II & 10.3 & 1.77 & 13.1 & 18.3 \\
4 & II & 10.4 & 1.46 & 9.9 & 15.1 \\
5 & III & 13.9 & 1.56 & 12.6 & 21.6 \\
6 & III & 12.2 & 2.06 & 15.0 & 25.2 \\
7 & IV & 14.0 & 2.18 & 21.6 & 30.6 \\
8 & IV & 22.7 & 1.18 & 17.0 & 26.7 \\
\hline
\end{tabular}

* B, P, S and BP are defined in Table IV.

values of $\mathrm{P}$ and $\mathrm{S}$ have also been computed as shown in Table V. Again with the exception of Study 8 , the reproducibility of computed values is good.

Concerning the model in general, it is clear that the experimental data do not fit the equations of the model, particularly during the early part of the experiment (as shown by the variability of B computed at different times or by other methods) because of the errors inherent in the assumptions. The computed values, although erroneous in terms of their original definitions, are representative of these defined magnitudes. The relative constancy of the values in one patient under repeated study suggests that this method of approach measures the same thing in a particular individual from time to time. When the same individual is studied under different conditions, it seems probable that many of the errors in the model will "cancel each other out" allowing the effect of applied variables on the physiology of nitrogen to be detected readily. Previous studies using the model $(12,13)$ have produced data in accord with physiologic expectations.

Concerning dietary changes, the specific questions approached here were: 1) What are the changes resulting from doubling the protein intake at two different levels of caloric intake? 2) Are kinetic changes in the organism mediated through changes in rate constants, pool sizes or both? The present data, although of a preliminary nature, suggest that the rate constant (B) for metabolic pool turnover is relatively constant and unaffected by changes in both caloric and protein intake over the range of dietary variation and period of time studied (Table III). The metabolic pool size $(\mathrm{P})$ and turnover rate $(\mathrm{BP})$ appear to increase somewhat when the dietary protein is increased from $40 \mathrm{Gm}$. per day to 80 $\mathrm{Gm}$. per day. The mean value of $\mathrm{P}$ in Studies 1 through 4 (Table IV) differed significantly from that of 5 through 8 at the 5 per cent level by the "t test." The rate of incorporation of nitrogen (S) (Table IV) appears to be unaffected by dietary changes until both nitrogen intake and caloric intake are raised (Studies 7 and 8). The mean value of $S$ for Studies 7 and 8 differed significantly from that of Studies 1 through 6 by the " $t$ test" at the 1 per cent level.

$S$ did not change significantly when the per cent of protein in the diet was doubled with maintenance of constant caloric intake (Studies 5 and 6). If caloric expenditures were equal on Diets II and III [and measurements by the technique of Johnson and Newburgh (4) suggest that they were], then a greater fraction of the caloric demand was provided by protein on the higher protein diet (Diet III). This is to be expected and is in keeping with the increased urea and total nitrogen excretion observed on Diet III. The relative constancy of $S$ on both diets also suggests that the additional protein was used to meet caloric needs and not for incorporation. It is well known that during starvation calories are furnished through breakdown of protein. Since synthetic processes require caloric expenditure, one would expect caloric needs to supersede to some extent synthetic processes. Here the individual maintained a steady state because the diet contained sufficient total calories including protein to meet caloric needs, some of which were derived from protein.

Since the total nitrogen excretion on Diets III and IV was the same, and the urea excretion was slightly greater on Diet IV (Table III), one might expect the same or slightly less nitrogen available for incorporation on Diet IV. The greater incorporation into protein (S) calculated therefore corresponds to more rapid turnover of the metabolic pool (BP) associated with the higher caloric intake.

Although S increased somewhat in Studies 7 and 8 , the patient was in nitrogen equilibrium. This raises the question of whether high nitrogen and high caloric intake can increase protein turnover when there is no demonstrable increase in 
the amount of protein in the body. It is of interest that this patient, after discharge from the hospital, gained $7 \mathrm{Kg}$. over the course of several months. The question also arises as to whether increased protein turnover is a prelude to positive nitrogen balance. Considerably more study will be necessary before these questions can be answered definitively.

\section{SUMMARY}

1. The mathematical model of nitrogen metabolism devised by San Pietro and Rittenberg (1) has been examined from the theoretical and experimental standpoint.

2. The reproducibility of calculated values for nitrogenous metabolic pool size $(P)$, rate of incorporation of nitrogen into protein (S), and rate constant for nitrogenous metabolic pool turnover (B) in one individual under the same conditions is adequate enough to suggest that the effect of variables on the kinetics of nitrogen metabolism can be readily determined.

3. The effect of variation in both caloric and protein content of the diet was determined while the patient was on a metabolic balance study. The rate constant for nitrogenous metabolic pool turnover does not appear to vary significantly with the changes of diet studied here. Increased protein intake appears to increase the size of the nitrogenous metabolic pool $(\mathrm{P})$ somewhat. The calculated rate of incorporation of nitrogen into protein (S) increased when both the caloric and protein intake were increased, even though the patient remained in nitrogen equilibrium. This raises the question as to whether increased caloric and protein intake can increase protein turnover prior to the onset of positive nitrogen balance.

\section{REFERENCES}

1. San Pietro, A., and Rittenberg, D. A study of the rate of protein synthesis in humans. II. Measurement of the metabolic pool and the rate of protein synthesis. J. biol. Chem. 1953, 201, 457.
2. Olesen, K., Heilskov, N. C. S., and Schoenheyder, F. The excretion of $\mathrm{N}^{15}$ in urine after administration of $\mathrm{N}^{15}$ glycine. Biochim. biophys. Acta 1954, 15, 95.

3. Watkin, D. M., and Silver, R. T. Nitrogen, mineral, uric acid and basal metabolism studies in a case of adult acute leukemia with extensive osteolytic bone disease. Amer. J. Med. 1958, 24, 638.

4. Johnson, M. W., and Newburgh, L. H. Calculation of heat production from insensible loss of weight. J. clin. Invest. 1942, 21, 357.

5. Wu, H., and Rittenberg, D. Metabolism of L-aspartic acid. J. biol. Chem. 1949, 179, 847.

6. Fosse, R. Origine et distribution de l'uree dans la nature. Application de nouvelles methodes d'analyse de l'uree basees sur l'emploi du xanthydrol. Ann. Chem. 1916, 6, 13.

7. Vanselow, A. P. Preparation of Nessler's Reagent. Industr. engin. Chem. Analyt. Ed. 1940, 12, 516.

8. Prentice, T. C., Siri, W., Berlin, N. I., Hyde, G. M., Parsons, R. J., Joiner, E. E., and Lawrence, J. H. Studies of total body water with tritium. J. clin. Invest. 1952, 31, 412.

9. Peters, J. P., and Van Slyke, D. D. Quantitative Clinical Chemistry, Vol. 2. Baltimore, Williams and Wilkins, 1932, p. 527.

10. Reiner, J. M. The study of metabolic turnover rates by means of isotopic tracers. I. Fundamental relations. Arch. Biochem. 1953, 46, 53.

11. Reiner, J. M. The study of metabolic turnover rates by means of isotopic tracers. II. Turnover in a simple reaction system. Arch. Biochem. 1953, 46, 80.

12. Crispell, K. R. General discussion of growth hormone and energy sources in Hypophyseal Growth Hormone, Nature and Actions, R. W. Smith, Jr., O. H. Gaebler and C. N. H. Long, Eds. New York, McGraw-Hill Company, 1955, p. 252.

13. Crispell, K. R., Parson, W., and Hollifield, G. A study of the rate of protein synthesis before and during the administration of 1-triiodothyronine to patients with myxedema and healthy volunteers using $\mathrm{N}^{15}$ glycine. J. clin. Invest. 1956, 35, 164.

14. Reifenstein, E. C., Jr., Albright, F., and Wells, S. L. The accumulation, interpretation, and presentation of data pertaining to metabolic balances, notably those of calcium, phosphorus, and nitrogen. J. clin. Endocr. 1945, 5, 367.

15. Insull, W., Jr. Indirect calorimetry by new techniques: A description and evaluation. U. S. Army Medical Nutrition Laboratory Report, No. 146, 1954. 